\title{
Dissemination of bla $\mathrm{NDM}-1_{1}$ Gene Among Several Klebsiella pneumoniae Sequence Types in Mexico Associated With Horizontal Transfer Mediated by IncF-Like Plasmids
}

OPEN ACCESS

Edited by:

Sheng Chen,

City University of Hong Kong,

Hong Kong

Reviewed by:

Carlos Henrique Camargo,

Adolfo Lutz Institute, Brazil

Yunsong Yu,

Zhejiang University, China

*Correspondence:

María Dolores Alcántar-Curiel alcantar@unam.mx

Specialty section:

This article was submitted to

Antimicrobials, Resistance

and Chemotherapy,

a section of the journal

Frontiers in Microbiology

Received: 28 September 2020

Accepted: 28 February 2021

Published: 25 March 2021

Citation:

Toledano-Tableros JE,

Gayosso-Vázquez C

Jarillo-Quijada MD,

Fernández-Vázquez JL,

Morfin-Otero R, Rodríguez-Noriega E,

Giono-Cerezo S, Gutkind G,

Di Conza J, Santos-Preciado Jl and

Alcántar-Curiel MD (2021)

Dissemination of blandM-1 Gene Among Several Klebsiella pneumoniae

Sequence Types in Mexico

Associated With Horizontal Transfer

Mediated by IncF-Like Plasmids.

Front. Microbiol. 12:611274.

doi: 10.3389/fmicb.2021.611274
José Eduardo Toledano-Tableros 1,2, Catalina Gayosso-Vázquez', Ma Dolores Jarillo-Quijada', José Luis Fernández-Vázquez', Rayo Morfin-Otero3, Eduardo Rodríguez-Noriega ${ }^{3}$, Silvia Giono-Cerezo르, Gabriel Gutkind ${ }^{4}$, José Di Conza ${ }^{4}$, José Ignacio Santos-Preciado ${ }^{1}$ and María Dolores Alcántar-Curiel ${ }^{\text {* }}$

\footnotetext{
' Laboratorio de Infectología, Microbiología e Inmunología Clínicas, Unidad de Investigación en Medicina Experimental, Facultad de Medicina, Universidad Nacional Autónoma de México, Ciudad de México, Mexico, ${ }^{2}$ Departamento de Microbiología, Escuela Nacional de Ciencia Biológicas, Instituto Politécnico Nacional, Ciudad de México, Mexico, ${ }^{3}$ Hospital Civil de Guadalajara "Fray Antonio Alcalde" e Instituto de Patología Infecciosa y Experimental, Centro Universitario de Ciencias de la Salud, Universidad de Guadalajara, Guadalajara, Mexico, ${ }^{4}$ Laboratorio de Resistencia Bacteriana, Facultad de Farmacia y Bioquímica de la Universidad de Buenos Aires, Buenos Aires, Argentina
}

Nosocomial infections caused by multidrug-resistant (MDR) Klebsiella pneumoniae are a major health problem worldwide. The aim of this study was to describe NDM-1producing $K$. pneumoniae strains causing bacteremia in a tertiary referral hospital in Mexico. MDR K. pneumoniae isolates were screened by polymerase chain reaction for the presence of resistance genes. In resistant isolates, plasmids were identified and conjugation assays were performed. Clonal diversity and the sequence types were determined by pulsed-field gel electrophoresis and multilocus sequence typing. A total of $80 \mathrm{~K}$. pneumoniae isolates were collected from patients with bacteremia over a 1-year period. These isolates showed a level of resistance of $59 \%(47 / 80)$ to aztreonam, 56-60\% (45-48/80) to cephalosporins, 54\% (43/80) to colistin and 12.5\% $(10 / 80)$ to carbapenems. The carbapenem resistant isolates were bla $\mathrm{NDM}_{-1}$ carriers and negative for bla KPC $_{\text {, bla }}$ NDM, bla IMP $_{1}$ blavIM and bla OXA-48-like carbapenemases genes. Conjugative plasmids IncFIIA and IncF group with sizes of 82-195 kbp were carriers of bla $a_{\mathrm{NDM}-1}$, bla $\mathrm{C}_{\mathrm{CT}-\mathrm{M}-15}$, bla $\mathrm{TEM}_{\mathrm{T}-1}$, aac(6')-Ib and/or aac(3')-Ila. Clonal variability and nine different multilocus sequence types were detected (ST661, ST683, ST1395, ST2706, ST252, ST1198, ST690, ST1535, and ST3368) for the first time in the isolates carrying bla $\mathrm{NDM}-1_{1}$ in Mexico. This study demonstrates that bla $a_{\mathrm{NDM}-1}$ has remained within this hospital in recent years and suggests that it is currently the most prevalent carbapenemase among $K$. pneumoniae MDR strains causing bacteremia in Mexico. The horizontal transfer of bla $\mathrm{NDM}_{-1}$ gene through IncF-like plasmids among different clones demonstrates the dissemination pathway of antimicrobial resistance 
and underscore the need for strong and urgent joint measures to control the spread of NDM-1 carbapenemase in the hospital.

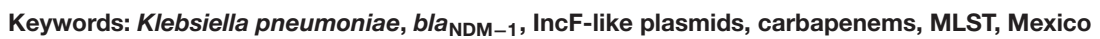

\section{INTRODUCTION}

Klebsiella pneumoniae (K. pneumoniae) is the causative agent of community and hospital acquired infections (Ramirez et al., 2019). In recent years, this bacterium has acquired high resistance to broad-spectrum antibiotics such as $\beta$-lactams, aminoglycosides, and quinolones (Ferreira et al., 2019). At the present time, the spread of carbapenemase-producing $K$. pneumoniae is a global public health concern (Villa et al., 2017). Klebsiella pneumoniae carbapenemase (KPC) was first reported in North Carolina in 2001. In the last decade it has disseminated globally due to the clonal spread of KPC-producing $K$. pneumoniae and in some countries its nosocomial dissemination has caused outbreaks (Martin et al., 2017). In Mexico, the first report of KPC-3-producing K. pneumoniae causing an outbreak was in 2013 (RodríguezZulueta et al., 2013). Two subsequent works have reported the presence of a small number of strains of $K$. pneumoniae producing this carbapenemase (Bocanegra-Ibarias et al., 2017; Aquino-Andrade et al., 2018). One of the carbapenemases initially described in K. pneumoniae is New Delhi metallo$\beta$-lactamase 1 (NDM-1), the dissemination of which is mostly hospital associated (Politi et al., 2019). The prevalence of carbapenemases in K. pneumoniae has been little studied in Mexico, however, recent research has demonstrated that NDM-1 carbapenemase is more frequent than that of KPC (RodríguezZulueta et al., 2013; Bocanegra-Ibarias et al., 2017; AquinoAndrade et al., 2018; Alcántar-Curiel et al., 2019b), which has been reported as endemic in the United States, Brazil, Argentina, Colombia and sporadically in Canada (Lee et al., 2016; Hammoudi Halat and Ayoub Moubareck, 2020).

Although bla $a_{\mathrm{NDM}-1}$ has been found on the bacterial chromosome, the vast majority is carried on plasmids (Wu et al., 2019). Currently there are 20 different incompatibility groups (Inc) of bla $\mathrm{NDM}-1_{1}$ carrying plasmids in Enterobacteriaceae, including IncA/C, IncFIA, IncFIB, IncFII and IncX3 (Wu et al., 2019), indicating the different possibilities of acquisition of $b l a_{\mathrm{NDM}-1}$ and the horizontal spread between bacteria of the same or different species.

In addition to this phenomenon, some $K$. pneumoniae carbapenemase producers are defined as high-risk clones because of their ability to colonize, spread and persist (Pitout et al., 2015). The multilocus sequence types (ST) ST258, and ST11, both belonging to the clonal complex (CC) 258, are prototypes of an epidemic clone which was identified as early 2000s and are currently spread around the world (Pitout et al., 2015; Lee et al., 2016).

The aims of this study were to investigate antimicrobial resistant genes, the plasmids associated with horizontal gene transfer and to determine the expansion of multilocus sequence types in K. pneumoniae causing bacteremia in a tertiary referral hospital in Mexico.

\section{MATERIALS AND METHODS}

\section{Bacterial Isolation}

Non-duplicate isolates of $K$. pneumoniae were consecutively collected from all blood cultures of patients with nosocomial bacteremia identified from January to December 2017 at Hospital Civil de Guadalajara, an 899-bed tertiary-care teaching hospital in Guadalajara, Jalisco, Mexico. The hospital infrastructure is made up of two buildings, the old, the architecture of the building is mixed, horizontal in its old area and a vertical tower of specialties with ten levels, also there is a building for the Care of Neonates and Women, an outpatient tower, the ophthalmology Unit and a Geriatric Care Unit.

Nosocomial infections were defined according to criteria published by the Centers for Disease Control and by Infectious Diseases Unit physicians (Horan et al., 2008). The isolates were stored in Luria Bertani (LB) broth (Difco, BD Biosciences, Franklin Lakes, NJ, United States) with 20\% glycerol (SigmaAldrich, St. Louis, $\mathrm{MO}$, United States) at $-70^{\circ} \mathrm{C}$.

\section{Antimicrobial Susceptibility Testing}

Identification and antimicrobial susceptibility against piperacillin-tazobactam, aztreonam, cefazolin, cefepime, ceftriaxone, ceftolozane-tazobactam, imipenem, meropenem, ciprofloxacin, amikacin, gentamycin, tobramycin, nitrofurantoin, tigecycline and trimethoprim-sulfamethoxazole were performed using the Vitek $^{\circledR} 2$ system (BioMérieux Durham, NC, United States). Minimal inhibitory concentrations (MIC) of colistin were determined by a microdilution method following the guidelines of the Clinical and Laboratory Standard Institute (CLSI, 2018). The production of extended spectrum $\beta$-lactamases (ESBLs) was confirmed phenotypically in all isolates resistant to penicillin/tazobactam and cephalosporins using the agar diffusion method (CLSI, 2018). Metallo$\beta$-lactamases (MBLs) production in carbapenem-resistant isolates was determined by the diffusion test on agar using meropenem and imipenem sensidisks with or without $0.5 \mathrm{M}$ EDTA and in combination with $400 \mu \mathrm{g} / \mathrm{mL}$ of phenylboronic acid for the presumptive identification of carbapenemase KPC (Alcántar-Curiel et al., 2019a).

\section{Detection of Resistance Genes}

Genes that encode antimicrobial resistance were detected by polymerase chain reaction (PCR) assay described previously (Alcántar-Curiel et al., 2019b). The presence of carbapenemase genes $b l a_{\mathrm{KPC}}, b l a_{\mathrm{NDM}}, b l a_{\mathrm{IMP}}, b l a_{\mathrm{VIM}}$ and $b l a_{\mathrm{OXA}}-48-$ like was determined by multiplex PCR (Poirel et al., 2011). Endpoint PCR was performed to detect $b l a_{\mathrm{TEM}}, b l a_{\mathrm{CTX}-\mathrm{M}}$. Additional genes of aminoglycoside modifying enzymes (AMEs) genes $a a c\left(3^{\prime}\right)-I a, a a c\left(6^{\prime}\right)-I I b$, the methyltransferases genes $r m t B$ and $\operatorname{armA}$ and the colistin resistance $m c r-1$ gene (Liu et al., 2016) 
were included in order to further characterize the strains. The specific oligonucleotides used are described in Supplementary Table 1. The amplified fragments were purified using the Zymogen Purification Kit (Promega) and sequenced (Instituto de Biotecnología, Universidad Nacional Autónoma de México). The sequence analysis was performed with the BioEdit and Kaling bioinformatics tools to subsequently undergo a Basic Local Alignment Search Tool (BLAST) in the National Center for Biotechnology Information database ${ }^{1}$.

\section{Plasmid Analysis and Conjugation Assays}

Plasmids profile was obtained from isolates carrying ESBLs or MBLs according to Eckhardt technique (Eckhardt, 1978). Horizontal transfer of antibiotic resistant was confirmed by bacterial conjugation with Escherichia coli J53-2 as the recipient strain using Miller method (Miller, 1992). Transconjugants were selected on McConkey agar supplemented with rifampicin (200 $\mu \mathrm{g} / \mathrm{mL})$ plus ceftazidime $(16 \mu \mathrm{g} / \mathrm{mL})$ and plus meropenem (16 $\mu \mathrm{g} / \mathrm{mL}$ ) for isolates that were carrying carbapenemases genes and tested for antimicrobial susceptibility. Successful conjugation was confirmed by specific PCR amplification and the electrophoretic pattern of the conjugated plasmids was obtained. The bacterial artificial chromosomes (BACs) of $67,86,101,122,145$, and $195 \mathrm{~kb}$ were used as a molecular weight markers (González et al., 2006). Plasmids of transconjugant strains were purified using the QIAGEN Plasmid Midi Kit (Qiagen, Hilden, Germany), following the manufacturer's specifications. Plasmids diversity was determined by restriction fragment length polymorphism (RFLP) (Ho et al., 2012) with EcoRI and HindIII (Invitrogen) restriction enzymes following the manufacturer's specifications. Finally, the groups Inc of conjugative plasmids were determined by PCR-based replicon typing (Carattoli et al., 2005).

\section{Genotyping by Pulsed-Field Gel Electrophoresis}

Clonality among all of the isolates was determined by pulsedfield gel electrophoresis (PFGE) (Alcántar-Curiel et al., 2019a). Chromosomal DNA of each isolate was prepared as described previously (Miranda et al., 1996) and macrorestricted with the restriction endonuclease XbaI (New England Biolabs, Beverly, MA, United States). Restriction fragments were resolved in a Gene Path System (BioRad ${ }^{\circledR}$, Hercules, CA, United States). The classification of the isolates in clones was based on Tenover criteria (Tenover et al., 1995). The percentage of similarity profile was calculated using the Dice coefficient. Isolates with a Dice similarity coefficient $>85 \%$ were considered as members of the same clone (Alcántar-Curiel et al., 2019a).

\section{Multilocus Sequence Typing}

To determine the sequence type (ST) of K. pneumoniae isolates harboring $b l a_{\mathrm{NDM}-1}$, MLST was performed according to the Pasteur scheme (Diancourt et al., 2005). The housekeeping

${ }^{1}$ www.ncbi.nlm.nih.gov/blast/ genes (gapA, infB, $m d h$, pgi, phoE, rpoB, ton $B)$ were amplified, sequenced, and analyzed with the MLST database of the Pasteur Institute to identify allelic profile. In order to identify the clonal complex (CC) and visualize evolutionary relationships among isolates carrying $b l a_{\mathrm{NDM}-1}$, we used Phyloviz 2.0 program that generates eBURST and neighbor-joining diagram (Sepp et al., 2019).

\section{RESULTS}

\section{Clinical Isolates and Antibiotic Susceptibility Pattern}

A total of 80 isolates of $K$. pneumoniae causing bacteremia were collected over the course of 1 year at the Hospital Civil de Guadalajara. These isolates representing $8 \%$ of the total documented bacteremias. K. pneumoniae were more frequently derived in patients from surgical ward (32.5\%) and medicine ward (31.2\%) (Table 1 and Supplementary Data Sheet 1). The isolates were resistant to penicillin/tazobactam 26\% (21/80), aztreonam 59\% (47/80), cefepime 56\% (45/80), ceftriaxone $60 \%$ (48/80), imipenem and meropenem 12.5\% (10/80), ciprofloxacin $18 \%$ (14/80), tobramycin 50\% (40/80), gentamicin 55\% (44/80), nitrofurantoin $16 \%(13 / 80)$, tigecycline 5\% (4/80), trimethoprimsulfamethoxazole 56\% (45/80) and colistin 53\% (42/80) (Table 2).

\section{Antibiotic Resistance Enzymes}

A total of 10 strains resistant to all $\beta$-lactams including the two carbapenems were detected. These strains were MBL producers and carried the $b l a_{\mathrm{NDM}-1}$ carbapenemase gene (Supplementary Data Sheet 1). Furthermore, three of these strains carried the $b l a_{\mathrm{TEM}-1}$ penicillinase gene and four strains $b l a_{\mathrm{TEM}-1}$ and

TABLE 1 | Frequency of bla NDM-1-producing Klebsiella pneumoniae isolates in the different hospital setting.

\begin{tabular}{|c|c|c|}
\hline Hospital wards & Area & No. isolates (\%) \\
\hline Surgical & & $26(32.5)$ \\
\hline Neurology (NEU) & Old & $13(16)$ \\
\hline General surgery (GES) & Old & $10(12.5)$ \\
\hline Plastic surgery (PSU) & Old & $1(3.8)$ \\
\hline Oral and maxillofacial surgery (OMS) & Old & $1(1.3)$ \\
\hline Otorhinolaryngology (OTO) & Old & $1(3.8)$ \\
\hline Medicine & & $25(31.2)$ \\
\hline Internal medicine (IME) & Old & $7(8.4)$ \\
\hline Cardiology (CAR) & Old & $5(6.3)$ \\
\hline Nephrology (NEP) & Tower 5 floor & $5(6.3)$ \\
\hline Haematology (HEM) & Tower 9 floor & $3(3.8)$ \\
\hline Infectious diseases unit (IDU) & Tower 7 floor & $3(3.8)$ \\
\hline Gastroenterology (GAS) & Tower 6 floor & $1(1.3)$ \\
\hline HIV/AIDS Unit (HIV) & & $1(1.3)$ \\
\hline Pediatric intensive care unit & & $20(25)$ \\
\hline Neonatal intensive care unit (NICU) & Newborn unit & $13(16.2)$ \\
\hline Pediatric intensive care unit (PICU) & Tower 1 floor & $7(8.7)$ \\
\hline Intensive Care Unit (ICU) & Tower 1 floor & $9(11.2)$ \\
\hline Total & & $80(100)$ \\
\hline
\end{tabular}


TABLE 2 | Minimum inhibitory concentration data and antimicrobial susceptibility of 80 Klebsiella pneumoniae isolates from January to December 2017 at Hospital Civil de Guadalajara.

\begin{tabular}{|c|c|c|c|c|c|c|}
\hline \multirow[t]{2}{*}{ Drug class } & \multirow[t]{2}{*}{ Antimicrobial agent } & \multicolumn{2}{|c|}{$M I C^{\star}(\mu \mathrm{g} / \mathrm{mL})$} & \multicolumn{3}{|c|}{ Antimicrobial susceptibility (\%) } \\
\hline & & $\mathrm{MIC}_{90}$ & $\mathrm{MIC}_{50}$ & Susceptible & Intermediate & Resistant \\
\hline$\beta$-lactam combination agents & Piperacillin/Tazobactam & 128 & 16 & 65 & 9 & 26 \\
\hline Monobactam & Aztreonam & 64 & 2 & 36 & 5 & 59 \\
\hline \multirow[t]{3}{*}{ Cephems } & Cefazolin & 64 & 8 & 41 & 0 & 59 \\
\hline & Cefepime & 64 & 2 & 44 & 0 & 56 \\
\hline & ceftriaxone & 64 & 32 & 40 & 0 & 60 \\
\hline$\beta$-lactam combination agents & Ceftolozane/Tazobactam* & $\mathrm{N} / \mathrm{A}$ & $\mathrm{N} / \mathrm{A}$ & 87 & 0 & 13 \\
\hline \multirow[t]{2}{*}{ Carbapenems } & Imipenem & 8 & 0.06 & 87 & 0 & 13 \\
\hline & Meropenem & 4 & 0.03 & 87 & 0 & 13 \\
\hline Fluoroquinolones & Ciprofloxacin & 4 & 1 & 68 & 14 & 18 \\
\hline \multirow[t]{3}{*}{ Aminoglycosides } & Amikacin & 128 & 8 & 56 & 0 & 24 \\
\hline & Gentamicin & 128 & 32 & 45 & 0 & 55 \\
\hline & Tobramycin & 32 & 1 & 50 & 0 & 50 \\
\hline Nitrofurans & Nitrofurantoin & 128 & 64 & 26 & 58 & 16 \\
\hline Glycylcycline & Tigecycline $e^{\star \star \star}$ & 2 & 1 & 91 & 4 & 5 \\
\hline Folate pathway antagonists & Trimethoprim/Sulfamethoxazole & $16 / 304$ & $16 / 304$ & 43 & 1 & 56 \\
\hline Lipopeptides & Colistin ${ }^{\star \star \star}$ & 32 & 4 & 47 & 0 & 54 \\
\hline
\end{tabular}

*Susceptibility breakpoint categories were derived from CLSI (2018).

**Susceptibility was determined by agar disk diffusion method.

${ }^{* * *}$ Susceptibility categorization was determined according to the EUCAST criteria.

N/A, Not applicable.

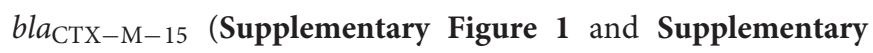
Data Sheet 1). Regarding to the 37 strains resistant to $\beta$-lactams but susceptible to carbapenems, $89 \%$ (33/37) were ESBL producers; 32 strains carried $b l a_{\mathrm{TEM}-1}$ and $b l a_{\mathrm{CTX}-\mathrm{M}-15}$ genes and one strain carried only bla $a_{\mathrm{CTX}-\mathrm{M}-15}$ (Supplementary Figure 1 and Supplementary Data Sheet 1 ).

In relation to the 55 isolates resistant to aminoglycosides tested, 56\% (31/55) were carriers of $\operatorname{aac}\left(3^{\prime}\right)-I I a$ and $\operatorname{aac}\left(6^{\prime}\right)$ IIb AME genes. AMEs genes were not detected in five isolates resistant only to amikacin and six isolates resistant to amikacin and gentamicin. $a a c\left(6^{\prime}\right)-I b$ was associated with resistance to tobramycin, while aac(3')-IIa was associated with resistance to gentamicin (Supplementary Table 2). Regarding the $m c r-1$ gene was not detected in 43 colistin-resistant isolates examined in this study.

\section{Plasmid Analysis}

Conjugation experiments in ten isolates $b l a_{\mathrm{NDM}-1}$ carriers showed that five transconjugants acquired the $b l a_{\mathrm{NDM}-1}$ gene (Table 3). Plasmid analysis indicated that one transconjugant harbored the $b l a_{\mathrm{NDM}-1}$ gene on a $\sim 82 \mathrm{kbp}$ plasmid. The other four transconjugants harbored the $b l a_{\mathrm{NDM}-1}$ gene on a $\sim 195 \mathrm{kbp}$ plasmid, only two of these plasmids were carriers of a single $b l a_{\mathrm{NDM}-1}$ resistance gene, the other plasmid was a carrier of both $b l a_{\mathrm{NDM}-1}$ and $b l a_{\mathrm{TEM}-1}$ genes and the fourth plasmid was a carrier of bla $a_{\mathrm{NDM}-1}, b l a_{\mathrm{TEM}-1}, b l a_{\mathrm{CTX}-\mathrm{M}-15}$ and $\operatorname{aac}\left(3^{\prime}\right)-I I a$ and $a a c\left(6^{\prime}\right)-I b$. All the five transconjugants were resistant to all $\beta$-lactams and aminoglycosides with the exception of one. Plasmid replicon typing showed that four of the conjugative plasmids belonged to the IncFIIA and one to the IncF group.
With respect to thirty-three $b l a_{\mathrm{TEM}-1}$ and $b l a_{\mathrm{CTX}-\mathrm{M}-15}$ carriers, 26 transconjugants were obtained (Supplementary Table 3), of which 13 harbored a $>195 \mathrm{kbp}$ plasmid, 12 carried a $\sim 195$ kbp plasmid and only one acquired a $\sim 67 \mathrm{kbp}$ plasmid. From the total 26 conjugative plasmids, 25 of them harbored the $b l a_{\mathrm{CTX}-\mathrm{M}-15}, b l a_{\mathrm{TEM}-1}, \operatorname{aac}\left(3^{\prime}\right)-I I a$ and $a a c\left(6^{\prime}\right)-I b$, and only one of them harbored the bla $a_{\mathrm{CTX}-\mathrm{M}-15}, b a_{\mathrm{TEM}-1}$ and $a a c\left(6^{\prime}\right)-I I a$. Twenty-five of these plasmids belonged to the IncF group and only one plasmid to the IncFIIA group.

Fragment length polymorphism (RFLP) analysis of the conjugative plasmids carrying both $b l a_{\mathrm{NDM}-1}$ and $b l a_{\mathrm{CTX}-\mathrm{M}-15}$ showed an average similarity of $88 \%$ (Figure 1). The five plasmids carriers $b l a_{\mathrm{NDM}-1}$ revealed two different restriction profiles (P), four of them belonged to P8. The 26 plasmids carriers of bla $a_{\mathrm{TEM}-1}$ and bla $a_{\mathrm{CTX}-\mathrm{M}-15}$ belonged to eight different restriction profiles.

\section{Clonality Analysis}

Pulsed-field gel electrophoresis (PFGE) analysis was conducted with an average similarity of $66 \%$. Sixty-nine different clones were detected among the 80 isolates, which showed clonal heterogeneity (data not shown). Clone 26 was the most prevalent with three isolates collected in May and June, all carriers of bla $a_{\mathrm{CTX}-\mathrm{M}-15}, b l a_{\mathrm{TEM}-1}, \operatorname{aac}\left(3^{\prime}\right)-I a$ and $a a c\left(6^{\prime}\right)-I I b$. Clones $6,15,34,35,37,39,42$, and 47 had two isolates each, while the rest of the isolates belonged to different clones (Supplementary Data Sheet 1). The 43 strains of K. pneumoniae carrying resistance genes belonged to 38 different clones, the 10 isolates carriers of bla $a_{\mathrm{NDM}-1}$ belonged to different clones (Supplementary Figure 1). 


\section{MLST Analysis}

The analysis demonstrated nine different STs among ten isolates carriers of bla $a_{\mathrm{NDM}-1}$ gene; ST661, ST683 belonged to CC258, ST1395, ST2706, ST252, ST1198, ST690, ST1535, and ST3368 (Supplementary Figure 2). Isolates 07-KP-17, and 11-KP-17 belonged to ST661 which corresponds to the founder member of CC661, these isolates were recovered in February and March 2017 respectively.

Phylogenetic analysis using the neighbor-joining method detected the genetic distance between the 10 isolates carriers of $b l a_{\mathrm{NDM}-1}$ gene (Figure 2). Isolates recovered in February and March as well as the isolates recovered between April and June were significantly associated, while the October isolates including the 69-KP-17 isolate were not.

\section{DISCUSSION}

Klebsiella pneumoniae is included in the global priority list of antibiotic resistant bacteria, and there is a need for enhanced $K$. pneumoniae surveillance to rapidly identify and monitor convergent strains and/or plasmids (Wyres et al., 2020). The infections caused by $K$. pneumoniae during the present study period were $8 \%$, lower than those reported for developing countries ranging from 16 to $28 \%$ (Khaertynov et al., 2018).

The rate of antimicrobial resistance observed in the isolates from our study was lower than the rate from the isolates that caused nosocomial outbreaks previously reported in the same hospital (Bocanegra-Ibarias et al., 2017). While this was a short study period, our findings are consistent with the high rate of resistance reported in Asia where they detected $60-75.8 \%$ to cephalosporins, $47-65.6 \%$ to imipenem and $40.8-76 \%$ to amikacin (Effah et al., 2020). Detection of $54 \%$ colistin resistance in this study is undoubtedly our biggest concern, a significant increase compared to the $4.7 \%$ reported 2 years earlier in this hospital (Bocanegra-Ibarias et al., 2017). This may be due to the increased use of colistin for the treatment of bacteremia caused by carbapenemase-producing isolates in hospital and because the isolates from the previous study were mostly derived from a nosocomial outbreak (Bocanegra-Ibarias et al., 2017).

The spread of NDM-producing bacteria and their association with nosocomial outbreaks is of concern worldwide (Dortet et al., 2014). The first report of NDM in K. pneumoniae was described in Mexico in 2014 (Barrios et al., 2014). The detection of $b l a_{\mathrm{NDM}-1}$ in ten isolates included in this study, demonstrates the spread and persistence of this carbapenemase among K. pneumoniae isolates for at least two consecutive years at Hospital Civil de Guadalajara (Bocanegra-Ibarias et al., 2017). Additionally, the co-transfer of $b l a_{\mathrm{NDM}-1}$ and AMEs genes together with fluoroquinolone resistance in 19-Kpn isolate (Table 3) demonstrates the concurrence of these genes, which represents a major challenge in the treatment of patients (Mitra et al., 2019).

It has been documented that in $K$. pneumoniae these resistance genes are encoded in small $25 \mathrm{kbp}$ conjugative plasmids or smaller (Ramirez et al., 2019), which contrasts with the >195 kbp conjugative plasmids identified in this 


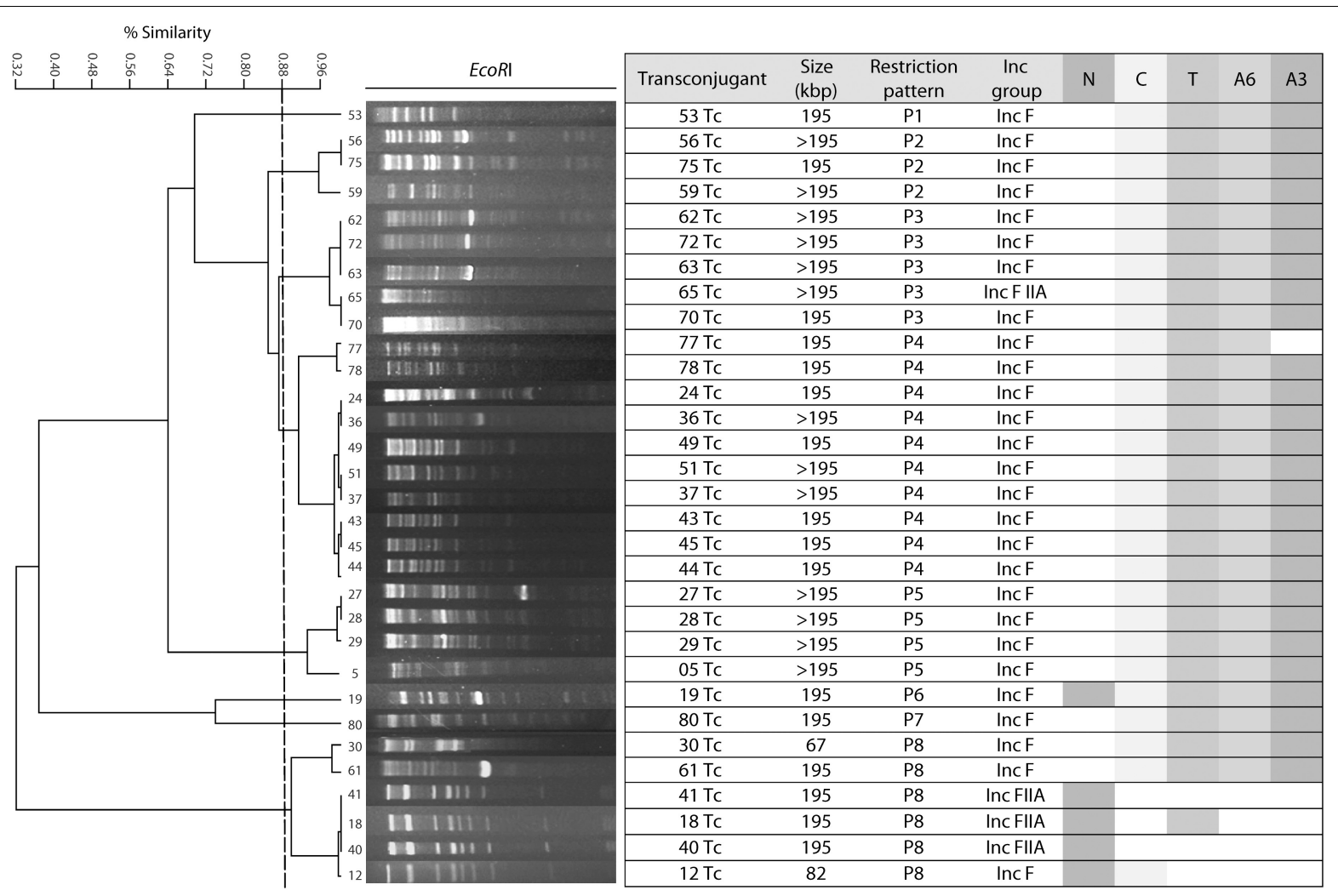

FIGURE 1 | Restriction fragment length polymorphism analysis of conjugative plasmids carrying antimicrobial resistance genes. N: bla $a_{N D M-1}, C: b / a_{C T X-M-15}$, T: blaTEM-1, A6: $\operatorname{aac}\left(6^{\prime}\right)-1 / b, A 3: \operatorname{aac}\left(3^{\prime}\right)-1 / a$.

study (Figure 1). RFLP analysis showed that isolates in our study harbor different types of plasmids carrying bla $a_{\mathrm{NDM}-1}$, ESBLs and AMEs, suggesting that genetic rearrangements occurred at the plasmid level during this period of study. Furthermore, similar plasmids were detected among different clones, which indicates that the transfer of genes is common among bacteria allowing the spread of resistance genes in the hospital environment.

The bla $a_{\mathrm{NDM}-1}$ gene has been identified in plasmids from different replicon types, in this study the plasmid carrying $b l a_{\mathrm{NDM}-1}$ gene belongs to the IncF and IncFIIA subgroups; which are different from the IncFIIk and IncFIIy subgroups previously reported in this hospital (Bocanegra-Ibarias et al., 2017) and the IncFIA reported in isolates in Mexico City (Alcántar-Curiel et al., 2019a).

The prevalence of plasmid replicons is led by the IncX group, while the IncF group ranks third, worldwide (Partridge et al., 2018; Wu et al., 2019). However, in Latin America, particularly in Mexico, Brazil, and Colombia, the IncF group seems be the most prevalent (Torres-González et al., 2015; Bocanegra-Ibarias et al., 2017; Alcántar-Curiel et al., 2019b; Wu et al., 2019).

In this study, gentamicin and tobramycin resistance was associated with the production of $\mathrm{AAC}\left(3^{\prime}\right)-\mathrm{II}$ a and $\mathrm{AAC}\left(6^{\prime}\right)-\mathrm{Ib}$, but not for amikacin resistance since the resistant isolates did not carry these genes studied (Supplementary Table 2). The five transconjugants of the isolates that produced ESBLs and were resistant to the 3 aminoglycosides acquired both AMEs but only had resistance to gentamicin and tobramycin (Table 2), suggests that amikacin resistance may be due to another AME or another resistance mechanism not encoded in plasmids. Because none of the studied AMEs were detected in transconjugants carriers $b l a_{\mathrm{NDM}-1}$ that acquired resistance to aminoglycosides, we consider that these isolates may carry others AMEs that were not investigated.

One of the most prevalent genes in Enterobacteriaceae, Pseudomonadales and Vibrionaceace worldwide is $a a c\left(6^{\prime}\right)-I b$ (Ramirez and Tolmasky, 2017; Fernández-Martínez et al., 2018; Galani et al., 2019), which is mostly associated with amikacin and gentamicin resistance (Ramirez and Tolmasky, 2017; Ramirez et al., 2019) and frequently encoded in plasmids and coexisting with ESBLs such as CTX-M. Our results are in agreement with these data with the exception that $a a c\left(6^{\prime}\right)-I b$ seems to be associated with tobramycin resistance since it was detected in isolates resistant only to this antibiotic. The observation that $\operatorname{aac}\left(3^{\prime}\right)-I I a$ is more frequent in Enterobacteriaceae and is associated with gentamicin and tobramycin resistance (Fernández-Martínez et al., 2018) is in agreement with our results.

Colistin resistance was not transferred by conjugation and this was supported by the fact that none of the isolates carried the mcr-1 gene, suggesting that resistance may be due to be associated with chromosomal mutations that are directly involved in LPS 


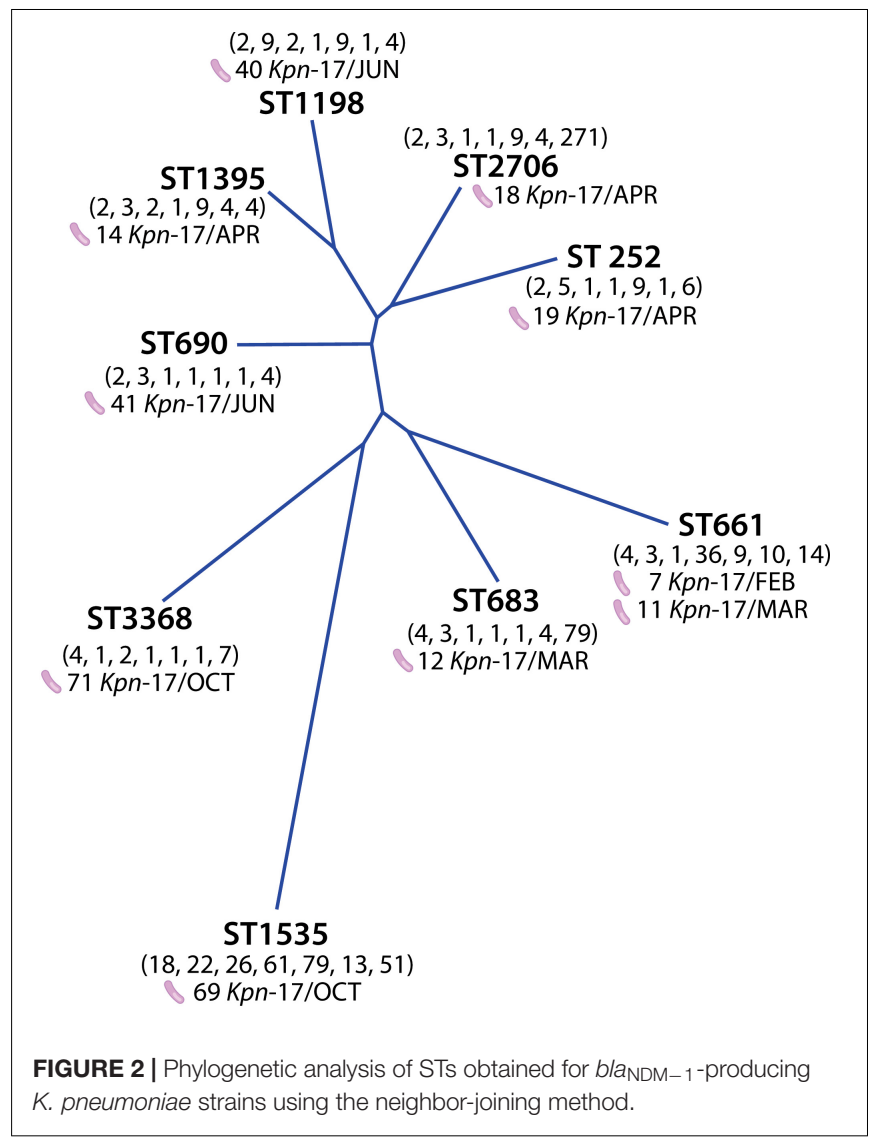

modifications such alteration in the MgrB gene, a very common colistin resistance mechanism in K. pneumoniae from the clinical setting (Luo et al., 2017).

Throughout our study, it was interesting to find that isolates showed a wide clonal diversity, including the carbapenem-resistant isolates which carried the $b l a_{\mathrm{NDM}-1}$ gene that has been frequently associated with outbreaks by K. pneumoniae (Dortet et al., 2014). However, the plasmids $b l a_{\mathrm{NDM}-1}$ carriers and other resistance genes were similar, their detection in different clones partially explains their dissemination in different clones, coinciding with previously report of bla $a_{\mathrm{NDM}-1}$ carriers Enterobacteriaceae in this hospital (Bocanegra-Ibarias et al., 2017).

The 9 STs detected in the ten $K$. pneumoniae carriers of $b l a_{\mathrm{NDM}-1}$ gene have not been previously described in Mexico (Barrios et al., 2014; Torres-González et al., 2015; BocanegraIbarias et al., 2017, 2019; Garza-Ramos et al., 2018). However, the isolate belonging to the ST683 is related to clonal complex 258, an epidemic clone with a global expansion. This clone is prevalent in Argentina and includes multi-drug resistant microorganisms that are KPC-producing and have been associated with high mortality rates (Cejas et al., 2019). Finally, three STs detected in this study (ST661, ST690, ST252) have been previously reported in other regions of the world although none of these K. pneumoniae strains carriers the bla $a_{\mathrm{NDM}-1}$ gene (Coelho et al., 2012; Papagiannitsis et al., 2015; Martin et al., 2017; Fu et al., 2018;
Marques et al., 2019; Piazza et al., 2019; Sghaier et al., 2019; Mori et al., 2020).

\section{CONCLUSION}

This study shows the prevalence of $K$. pneumoniae MDR isolates causing bacteremia in a tertiary referral hospital in Mexico. The carbapenem-resistant isolates were carriers of the $b l a_{\mathrm{NDM}-1}$ gene harbored in similar IncF-like plasmids among clones with different STs, which supports their nosocomial dissemination and persistence in different plasmids which can be associated with genetic rearrangements that might be in favor the microevolution of this nosocomial pathogen. These results underscore the importance of maintaining microbiological and epidemiological surveillance actions to detect and prevent the spread of MDR bacteria.

\section{DATA AVAILABILITY STATEMENT}

The original contributions presented in the study are included in the article/Supplementary Material, further inquiries can be directed to the corresponding author/s.

\section{ETHICS STATEMENT}

This study was evaluated and approved by the Institutional Research and Ethics Committee of the Hospital Civil de Guadalajara project number HCG/CEI-009316; 27 January 2016. The study does not involve humans it is an in vitro study. Written informed consent was not required for this study according to the institutional ethical, biosecurity and investigation committees because the Hospital Clinical Laboratory provided every bacterial isolates included in this study.

\section{AUTHOR CONTRIBUTIONS}

JET-T conceived and designed the study and performed the experiments, analyzed the data, and wrote and edited the manuscript. CG-V, MDJ-Q, JLF-V, and JDC performed the experiments, analyzed the data, and revised the manuscript. RM-O, ER-N, SG-C, GG, and JS-P analyzed the data and revised the manuscript. MA-C conceived, designed, and supervised the study, analyzed the data, and wrote and edited the manuscript. All authors contributed to the article and approved the submitted version.

\section{FUNDING}

This work was supported by Programa de Apoyo a Proyectos de Investigación e Innovación Tecnológica (UNAM-PAPIIT-DGAPA) grant number IN221617. JT$\mathrm{T}$ received fellowship (grant number 577332) from CONACYT for DSc studies and was supported by grant SIP20190120 from BEIFI-Instituto Politécnico Nacional. 
The work of JT-T at Universidad de Buenos Aires was supported, in part, by a short term exchange course provided by Union Iberoamericana de Universidades, Project INCAR (UIU-INCAR).

\section{ACKNOWLEDGMENTS}

We are grateful to Ing. Omar Agni García-Hernández from the Universidad Nacional Autónoma de México, Ciudad de México, for assistance with the graphic design.

\section{REFERENCES}

Alcántar-Curiel, M. D., Fernández-Vázquez, J. L., Toledano-Tableros, J. E., Gayosso-Vázquez, C., Jarillo-Quijada, M. D., López-Álvarez, M. D. R., et al. (2019a). Emergence of IncFIA plasmid-carrying bla $a_{\mathrm{NDM}-1}$ among Klebsiella pneumoniae and Enterobacter cloacae isolates in a tertiary referral hospital in Mexico. Microb. Drug Resist. 25, 830-838.

Alcántar-Curiel, M. D., Rosales-Reyes, R., Jarillo-Quijada, M. D., GayossoVázquez, C., Fernández-Vázquez, J. L., Toledano-Tableros, J. E., et al. (2019b). Carbapenem-resistant Acinetobacter baumannii in three tertiary care hospitals in Mexico: virulence profiles, innate immune response and clonal dissemination. Front. Microbiol. 10:2116. doi: 10.3389/fmicb.2019.02116

Aquino-Andrade, A., Merida-Vieyra, J., De La Garza, E. A., Arzate-Barbosa, P., and Ranero, A. D. C. (2018). Carbapenemase-producing Enterobacteriaceae in Mexico: report of seven non-clonal cases in a pediatric hospital. BMC Microbiol. 18:38. doi: 10.1186/s12866-018-1166-z

Barrios, H., Silva-Sanchez, J., Reyna-Flores, F., Sanchez-Perez, A., Sanchez-Francia, D., Aguirre-Torres, J. A., et al. (2014). Detection of a NDM-1-producing Klebsiella pneumoniae (ST22) clinical isolate at a pediatric hospital in Mexico. Pediatr. Infect. Dis. J. 33:335. doi: 10.1097/inf.0000000000000173

Bocanegra-Ibarias, P., Garza-Gonzalez, E., Morfin-Otero, R., Barrios, H., Villarreal-Trevino, L., Rodriguez-Noriega, E., et al. (2017). Molecular and microbiological report of a hospital outbreak of NDM-1-carrying Enterobacteriaceae in Mexico. PLoS One 12:e0179651. doi: 10.1371/journal. pone. 0179651

Bocanegra-Ibarias, P., Garza-Gonzalez, E., Padilla-Orozco, M., MendozaOlazaran, S., Perez-Alba, E., Flores-Trevino, S., et al. (2019). The successful containment of a hospital outbreak caused by NDM-1-producing Klebsiella pneumoniae ST307 using active surveillance. PLoS One 14:e0209609. doi: 10. 1371/journal.pone.0209609

Carattoli, A., Bertini, A., Villa, L., Falbo, V., Hopkins, K. L., and Threlfall, E. J. (2005). Identification of plasmids by PCR-based replicon typing. J. Microbiol. Methods 63, 219-228. doi: 10.1016/j.mimet.2005.03.018

Cejas, D., Elena, A., Nuñez, D. G., Platero, P. S., De Paulis, A., Magariños, F., et al. (2019). Changing epidemiology of kpc-producing Klebsiella pneumoniae in Argentina: emergence of hypermucoviscous st25 and high-risk clone st307. J. Glob. Antimicrob. Resist. 18, 238-242. doi: 10.1016/j.jgar.2019.06.005

CLSI (2018). Performance Standards for Antimicrobial Susceptibility Testing: Approved, 28th Edn. Wayne, PA: CLSI.

Coelho, A., Piedra-Carrasco, N., Bartolome, R., Quintero-Zarate, J., Larrosa, N., Cornejo-Sánchez, T., et al. (2012). Role of IncHI2 plasmids harbouring $b l a_{\mathrm{VIM}-1}, \quad b l a_{\mathrm{CTX}-\mathrm{M}-9}, \quad a a c\left(6^{\prime}\right)-I b$ and $q n r A$ genes in the spread of multiresistant Enterobacter cloacae and Klebsiella pneumoniae strains in different units at hospital Vall d'Hebron, Barcelona, Spain. Int. J. Antimicrob. Agents 39, 514-517. doi: 10.1016/j.ijantimicag.2012.01.006

Diancourt, L., Passet, V., Verhoef, J., Grimont, P. A. D., and Brisse, S. (2005). Multilocus sequence typing of Klebsiella pneumoniae nosocomial isolates. J. Clin. Microbiol. 43, 4178-4182. doi: 10.1128/jcm.43.8.4178-4182.2005

Dortet, L., Poirel, L., and Nordmann, P. (2014). Worldwide dissemination of the NDM-type carbapenemases in gram-negative bacteria. Biomed Res. Int. 2014:249856.

\section{SUPPLEMENTARY MATERIAL}

The Supplementary Material for this article can be found online at: https://www.frontiersin.org/articles/10.3389/fmicb. 2021.611274/full\#supplementary-material

Supplementary Figure 1 | Genetic relationship and molecular characteristics of the 43 strains of $K$. pneumoniae carrying bla $a_{\mathrm{NDM}-1}$ and other resistance genes.

Supplementary Figure 2 | Diagram of the different clonal complexes (CC) and the multilocus sequence types (STs) identified by eBURST in bla NDM-1-producing K. pneumoniae isolates. The ST (red circles) and the CC (green circles) obtained for each strain $2 \mathrm{~B}$.

Eckhardt, T. (1978). A rapid method for the identification of plasmid desoxyribonucleic acid in bacteria. Plasmid 1, 584-588. doi: 10.1016/0147$619 x(78) 90016-1$

Effah, C. Y., Sun, T., Liu, S., and Wu, Y. (2020). Klebsiella pneumoniae: an increasing threat to public health. Ann. Clin. Microbiol. Antimicrob. 19, 1-9. doi: 10.14302/issn.2690-4721.ijcm-19-3154

Fernández-Martínez, M., Ruiz Del Castillo, B., Lecea-Cuello, M. J., RodríguezBaño, J., Pascual, Á, Martínez-Martínez, L., et al. (2018). Prevalence of aminoglycoside-modifying enzymes in Escherichia coli and Klebsiella pneumoniae producing extended spectrum $\beta$-lactamases collected in two multicenter studies in Spain. Microb. Drug Resist. 24, 367-376.

Ferreira, R. L., Da Silva, B., Rezende, G. S., Nakamura-Silva, R., Pitondo-Silva, A., Campanini, E. B., et al. (2019). High prevalence of multidrug-resistant Klebsiella pneumoniae harboring several virulence and $\beta$-lactamase encoding genes in a Brazilian intensive care unit. Front. Microbiol. 9:3198. doi: 10.3389/fmicb.2018. 03198

Fu, L., Huang, M., Zhang, X., Yang, X., Liu, Y., Zhang, L., et al. (2018). Frequency of virulence factors in high biofilm formation bla $a_{\mathrm{KPC}-2}$ producing Klebsiella pneumoniae strains from hospitals. Microb. Pathog. 116, 168-172. doi: 10.1016/ j.micpath.2018.01.030

Galani, I., Nafplioti, K., Adamou, P., Karaiskos, I., Giamarellou, H., Souli, M., et al. (2019). Nationwide epidemiology of carbapenem resistant Klebsiella pneumoniae isolates from Greek hospitals, with regards to plazomicin and aminoglycoside resistance. BMC Infect. Dis. 19:167. doi: 10.1186/s12879-0193801-1

Garza-Ramos, U., Barrios-Camacho, H., Moreno-Dominguez, S., Toribio-Jimenez, J., Jardon-Pineda, D., Cuevas-Pena, J., et al. (2018). Phenotypic and molecular characterization of Klebsiella spp. isolates causing community-acquired infections. New Microbes New Infect. 23, 17-27. doi: 10.1016/j.nmni.2018.02. 002

González, V., Santamaría, R. I., Bustos, P., Hernández-González, I., Medrano-Soto, A., Moreno-Hagelsieb, G., et al. (2006). The partitioned Rhizobium etli genome: genetic and metabolic redundancy in seven interacting replicons. Proc. Natl. Acad. Sci. 103, 3834-3839. doi: 10.1073/pnas.0508502103

Hammoudi Halat, D., and Ayoub Moubareck, C. (2020). The current burden of carbapenemases: review of significant properties and dissemination among gram-negative bacteria. Antibiotics 9:186. doi: 10.3390/antibiotics 9040186

Ho, P.-L., Li, Z., Lo, W.-U., Cheung, Y.-Y., Lin, C.-H., Sham, P.-C., et al. (2012). Identification and characterization of a novel incompatibility group X3 plasmid carrying bla $a_{\mathrm{NDM}-1}$ in Enterobacteriaceae isolates with epidemiological links to multiple geographical areas in China. Emerg Microbes Infect. 1:e39.

Horan, T. C., Andrus, M., and Dudeck, M. A. (2008). CDC/NHSN surveillance definition of health care-associated infection and criteria for specific types of infections in the acute care setting. Am. J. Infect. Control 36, 309-332. doi: 10.1016/j.ajic.2008.03.002

Khaertynov, K. S., Anokhin, V. A., Rizvanov, A. A., Davidyuk, Y. N., Semyenova, D. R., Lubin, S. A., et al. (2018). Virulence factors and antibiotic resistance of Klebsiella pneumoniae strains isolated from neonates with sepsis. Front. Med. 5:225. doi: 10.3389/fmed.2018.00225

Lee, C.-R., Lee, J. H., Park, K. S., Kim, Y. B., Jeong, B. C., and Lee, S. H. (2016). Global dissemination of carbapenemase-producing Klebsiella pneumoniae: 
epidemiology, genetic context, treatment options, and detection methods. Front. Microbiol. 7:895. doi: 10.3389/fmicb.2016.00895

Liu, Y.-Y., Wang, Y., Walsh, T. R., Yi, L.-X., Zhang, R., Spencer, J., et al. (2016). Emergence of plasmid-mediated colistin resistance mechanism MCR-1 in animals and human beings in China: a microbiological and molecular biological study. Lancet Infect. Dis. 16, 161-168. doi: 10.1016/s1473-3099(15)00424-7

Luo, Q., Yu, W., Zhou, K., Guo, L., Shen, P., Lu, H., et al. (2017). Molecular epidemiology and colistin resistant mechanism of $\mathrm{mcr}$-positive and $\mathrm{mcr}$ negative clinical isolated Escherichia coli. Front. Microbiol. 8:2262.

Marques, C., Belas, A., Aboim, C., Cavaco-Silva, P., Trigueiro, G., Gama, L. T., et al. (2019). Evidence of sharing of Klebsiella pneumoniae strains between healthy companion animals and cohabiting humans. J. Clin. Microbiol. 57:e01537-18.

Martin, J., Phan, H. T., Findlay, J., Stoesser, N., Pankhurst, L., Navickaite, I., et al. (2017). Covert dissemination of carbapenemase-producing Klebsiella pneumoniae (KPC) in a successfully controlled outbreak: long-and shortread whole-genome sequencing demonstrate multiple genetic modes of transmission. J. Antimicrob. Chemother. 72, 3025-3034. doi: 10.1093/jac/ $\mathrm{dkx} 264$

Miller, J. (1992). Experiments in Molecular Genetics. Cold Spring Harbor, NY: Cold Spring Harbor Laboratory Press.

Miranda, G., Kelly, C., Solorzano, F., Leanos, B., Coria, R., and Patterson, J. E. (1996). Use of pulsed-field gel electrophoresis typing to study an outbreak of infection due to Serratia marcescens in a neonatal intensive care unit. J Clin. Microbiol. 34, 3138-3141. doi: 10.1128/jcm.34.12.3138-3141. 1996

Mitra, S., Mukherjee, S., Naha, S., Chattopadhyay, P., Dutta, S., and Basu, S. (2019). Evaluation of co-transfer of plasmid-mediated fluoroquinolone resistance genes and $b l a_{\mathrm{NDM}}$ gene in Enterobacteriaceae causing neonatal septicaemia. Antimicrob. Resist. Infect. Control 8:46.

Mori, N., Kagawa, N., Aoki, K., Ishi, Y., Tateda, K., and Aoki, Y. (2020). Clinical and molecular analyses of bloodstream infections caused by IMP metallo- $\beta$ lactamase-producing Enterobacteriaceae in a tertiary hospital in Japan. J. Infect. Chemother. 26, 144-147. doi: 10.1016/j.jiac.2019.07.017

Papagiannitsis, C. C., Dolejska, M., Izdebski, R., Dobiasova, H., Studentova, V., Esteves, F. J., et al. (2015). Characterization of pKP-M1144, a novel ColE1-like plasmid encoding IMP-8, GES-5, and BEL-1 $\beta$-lactamases, from a Klebsiella pneumoniae sequence type 252 isolate. Antimicrob. Agents Chemother. 59, 5065-5068. doi: 10.1128/aac.00937-15

Partridge, S. R., Kwong, S. M., Firth, N., and Jensen, S. O. (2018). Mobile genetic elements associated with antimicrobial resistance. Clin. Microbiol. Rev. 31:e00088-17.

Piazza, A., Comandatore, F., Romeri, F., Brilli, M., Dichirico, B., Ridolfo, A., et al. (2019). Identification of bla $a_{\mathrm{VIM}-1}$ gene in ST307 and ST661 Klebsiella pneumoniae clones in Italy: old acquaintances for new combinations. Microb. Drug Resist. 25, 787-790. doi: 10.1089/mdr.2018.0327

Pitout, J. D., Nordmann, P., and Poirel, L. (2015). Carbapenemase-producing Klebsiella pneumoniae, a key pathogen set for global nosocomial dominance. Antimicrob. Agents Chemother. 59, 5873-5884. doi: 10.1128/aac. 01019-15

Poirel, L., Walsh, T. R., Cuvillier, V., and Nordmann, P. (2011). Multiplex PCR for detection of acquired carbapenemase genes. Diagn. Microbiol. Infect. Dis. 70, 119-123. doi: 10.1016/j.diagmicrobio.2010.12.002

Politi, L., Gartzonika, K., Spanakis, N., Zarkotou, O., Poulou, A., Skoura, L., et al. (2019). Emergence of NDM-1-producing Klebsiella pneumoniae in Greece: evidence of a widespread clonal outbreak. J. Antimicrob. Chemother. 74, 21972202. doi: 10.1093/jac/dkz176

Ramirez, M. S., Iriarte, A., Reyes, R., Sherratt, D. J., and Tolmasky, M. (2019). Small klebsiella pneumoniae plasmids: neglected contributors to antibiotic resistance. Front. Microbiol. 10:2182. doi: 10.3389/fmicb.2019.02182

Ramirez, M. S., and Tolmasky, M. E. (2017). Amikacin: uses, resistance, and prospects for inhibition. Molecules 22:2267. doi: 10.3390/molecules22122267

Rodríguez-Zulueta, P., Silva-Sánchez, J., Barrios, H., Reyes-Mar, J., Vélez-Pérez, F., Arroyo-Escalante, S., et al. (2013). First outbreak of KPC-3-producing Klebsiella pneumoniae (ST258) clinical isolates in a Mexican medical center. Antimicrob. Agents Chemother. 57, 4086-4088. doi: 10.1128/aac.02530-12

Sepp, E., Andreson, R., Balode, A., Bilozor, A., Brauer, A., Egorova, S., et al. (2019). Phenotypic and molecular epidemiology of ESBL-, AmpC-, and carbapenemase-producing Escherichia coli in Northern and Eastern Europe. Front. Microbiol. 10:2465. doi: 10.3389/fmicb.2019.02465

Sghaier, S., Abbassi, M. S., Pascual, A., Serrano, L., Díaz-De-Alba, P., Said, M. B., et al. (2019). Extended-spectrum $\beta$-lactamase-producing Enterobacteriaceae from animal origin and wastewater in Tunisia: first detection of O25bB23-CTX-M-27-ST131 Escherichia coli and CTX-M-15/OXA-204-producing Citrobacter freundii from wastewater. J. Glob. Antimicrob. Resist. 17, 189-194. doi: 10.1016/j.jgar.2019.01.002

Tenover, F. C., Arbeit, R. D., Goering, R. V., Mickelsen, P. A., Murray, B. E., Persing, D. H., et al. (1995). Interpreting chromosomal DNA restriction patterns produced by pulsed-field gel electrophoresis: criteria for bacterial strain typing. J. Clin. Microbiol. 33, 2233-2239. doi: 10.1128/jcm.33.9.2233-2239.1995

Torres-González, P., Bobadilla-Del Valle, M., Tovar-Calderón, E., Leal-Vega, F., Hernández-Cruz, A., Martínez-Gamboa, A., et al. (2015). Outbreak caused by Enterobacteriaceae harboring NDM-1 metallo- $\beta$-lactamase carried in an IncFII plasmid in a tertiary care hospital in Mexico City. Antimicrob. Agents Chemother. 59, 7080-7083. doi: 10.1128/aac.00055-15

Villa, L., Feudi, C., Fortini, D., Brisse, S., Passet, V., Bonura, C., et al. (2017). Diversity, virulence, and antimicrobial resistance of the KPC-producing Klebsiella pneumoniae ST307 clone. Microb. Genom. 3:e000110.

Wu, W., Feng, Y., Tang, G., Qiao, F., Mcnally, A., and Zong, Z. (2019). NDM metallo- $\beta$-lactamases and their bacterial producers in health care settings. Clin. Microbiol. Rev. 32, e115-e118.

Wyres, K. L., Nguyen, T. N., Lam, M. M., Judd, L. M., Van Vinh Chau, N., Dance, D. A., et al. (2020). Genomic surveillance for hypervirulence and multi-drug resistance in invasive Klebsiella pneumoniae from South and Southeast Asia. Genome Med. 12:11.

Conflict of Interest: The authors declare that the research was conducted in the absence of any commercial or financial relationships that could be construed as a potential conflict of interest.

Copyright (C) 2021 Toledano-Tableros, Gayosso-Vázquez, Jarillo-Quijada, Fernández-Vázquez, Morfin-Otero, Rodríguez-Noriega, Giono-Cerezo, Gutkind, Di Conza, Santos-Preciado and Alcántar-Curiel. This is an open-access article distributed under the terms of the Creative Commons Attribution License (CC BY). The use, distribution or reproduction in other forums is permitted, provided the original author(s) and the copyright owner(s) are credited and that the original publication in this journal is cited, in accordance with accepted academic practice. No use, distribution or reproduction is permitted which does not comply with these terms. 